\title{
Studies directed towards conformationally restricted nucleosides
}

\author{
Anthony D.M. Curtis, Mark J. Humphries, and Christopher A. Ramsden* \\ School of Chemistry and Physics, Lennard-Jones Laboratories, Keele \\ University, Keele, Staffordshire ST5 5BG, United Kingdom \\ E-mail: c.a.ramsden@chem.keele.ac.uk
}

Dedicated to our friend and colleague Gurnos Jones on the occasion of his $70^{\text {th }}$ birthday

(received 30 Apr 00; accepted 20 Aug 00; published on the web 28 Aug 00)

\begin{abstract}
5-Nitroimidazoles can be transformed into a variety of heterocyclic systems via reduction to the corresponding 5-aminoimidazoles: 1-( $\beta$-D-ribofuranosyl)-5-nitroimidazole is a precursor of nucleosides and their analogues. Using this approach, potential routes to conformationally restricted 1-( $\beta$-D-ribofuranosyl)-5-nitroimidazole derivatives, which employ radical cyclisation as a key ring forming step, are investigated. Novel radical precursors which, because of the extreme acid sensitivity of 1-( $\beta$-D-ribofuranosyl)-5-nitroimidazoles, have to be prepared and manipulated under basic conditions are described and radical cyclisation investigated.
\end{abstract}

Keywords: Conformationally restricted nucleosides, 5-nitromidazoles, 1-( $\beta$-D-ribofuranosyl)-5nitroimidazole

\section{Introduction}

In previous studies we have shown that simple 5-aminoimidazoles 1 can be conveniently prepared from 5-nitroimidazoles 2 and that these amines are useful building blocks for the preparation of novel heterocyclic systems, including nucleoside analogues. ${ }^{1-3}$ Recently we have described a convenient synthetic approach to the biosynthetic purine precursor AIR (aminoimidazole ribonucleotide) via the 5-nitroimidazole $3{ }^{4}$ The availability of the derivative 3 led us to investigate routes to the conformationally restricted 5-nitroimidazole 4 which is of interest as a potential precursor to nucleoside analogues that are constrained to the anticonformation, ${ }^{5}$ which may be the preferred conformation for some enzyme substrates. In particular we have investigated intramolecular cyclisations of the nucleophilic radical 5 on to the 2-position of the electron-deficient imidazole ring. In order to generate the desired radical 5 it was necessary to protect the secondary alcohol functions of the ribofuranose derivative 3 prior to manipulation of the primary alcohol. Since we have previously established ${ }^{4}$ that the 5- 
nitroimidazole 3 is extremely sensitive to the presence of small traces of acid, which catalyses the formation of 4(5)-nitroimidazole $2(\mathrm{R}=\mathrm{H})$, this functionalisation needed to be carried out under basic conditions. In this paper we describe the preparation of some suitably functionalised novel 5-nitroimidazole derivatives and attempts to achieve the desired cyclisation.
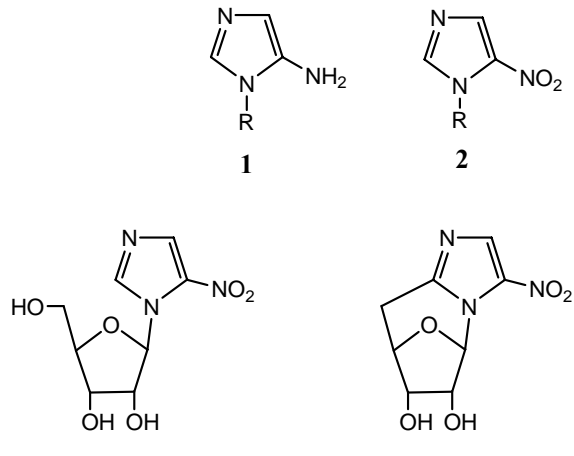

3

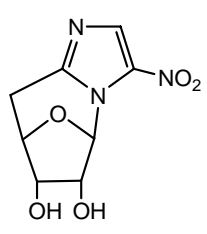

4

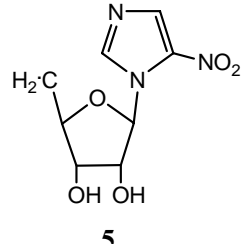

5

\section{Results and Discussion}

Our initial approach to protecting the secondary alcohol functions at positions $2^{\prime}$ and $3^{\prime}$ was to form a cyclic derivative but all attempts were unsatisfactory. Formation of the acetal 6 using 2,2dimethoxypropane and pyridinium $p$-toluenesulphonate as catalyst, which in contrast to $p$ toluene sulphonic acid is reported to be compatible with acid sensitive groups, ${ }^{6}$ gave no identifiable products. Attempts to form the cyclic carbonate 7 using trichloromethylchloroformate in dry pyridine were equally unsuccessful. Analyses of the reaction mixture by ${ }^{1} \mathrm{H}$ NMR and IR spectroscopy suggested that the desired product 7 had formed but only in very low yield. In a final attempt to form a cyclic derivative, compound 3 was treated with triethyl orthoformate in dry THF. After chromatography the desired product 8 (pale yellow syrup; $\mathrm{R}_{\mathrm{f}} 0.33$ ) was obtained as a mixture of diastereoisomers (40\% yield) ${ }_{\delta \mathrm{H}} \mathrm{C} 1$ ' $-\mathrm{H} 6.41$ and 6.47) but attempts to improve the yield and avoid the formation of alternative products were unsuccessful and this approach was abandoned.

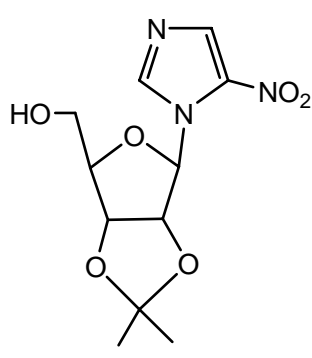

6

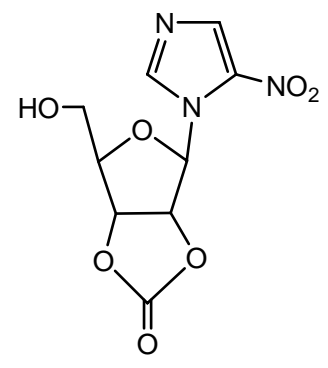

7

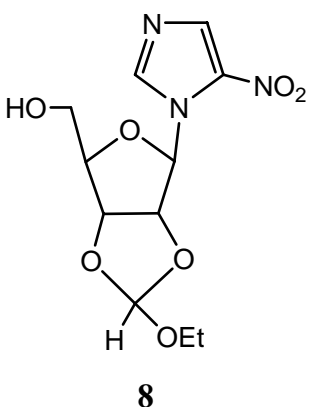

8 
Failure to synthesise a suitable 2',3'-derivative led us to then selectively protect the primary $5^{\prime}$-hydroxy group. An excellent protecting function for 5'-hydroxy is the dimethoxytrityl group ${ }^{7}$ but this requires removal by acid and was not suitable, therefore, for our purposes. Instead we chose to work with the $t$-butyldiphenylsilyl (TBDPS) protecting group which is readily removed using fluoride. The 5'-t-butyldiphenylsilyloxyribofuranose 9 was conveniently prepared by treatment of a mixture of the alcohol 3, triethylamine (1.2 equiv.) and dimethylaminopyridine (DMAP)(cat. amount) in dry DMF with t-butyldiphenylsilyl chloride. After chromatography the desired silylether 9 was obtained as a pure, crystalline compound that was identical to material that we subsequently prepared using an alternative procedure. ${ }^{4}$

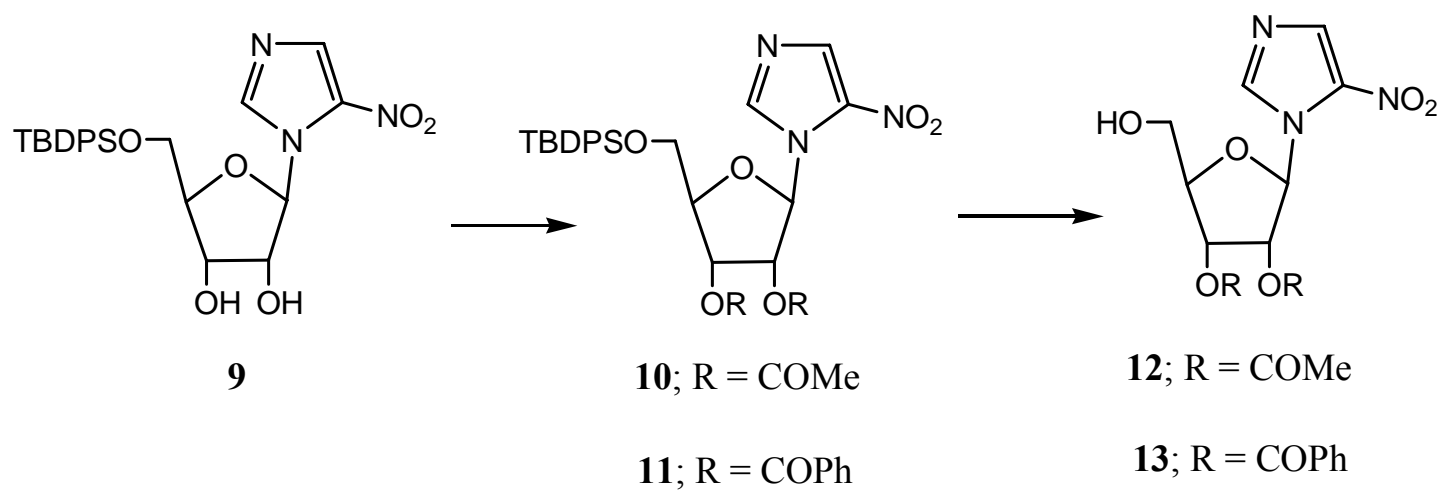

Having achieved selective blocking of the 5'-position we next investigated protection of the $2^{\prime}$ and $3^{\prime}$ hydroxy groups under basic conditions using protecting groups that would be stable under conditions required for removal of the 5'-silylether group. Compound 9 was acetylated using excess acetic anhydride and DMAP and under these conditions we obtained a quantitative yield of the derivative 10 which was isolated as a syrup and used without further purification. The structure and purity of product 10 was fully supported by ${ }^{1} \mathrm{H}$ NMR spectroscopy including the observation of two singlets at ${ }_{\delta \mathrm{H}} 2.11$ and 1.99 which were assigned to the $2^{\prime}$ and $3^{\prime}$ acetoxy substituents.

Treatment of a solution of compound 10 with tetra- $n$-butylammonium fluoride (TBAF) in THF solution resulted in complete disappearance of starting material (tlc) and formation of a mixture. The major component was isolated using short column chromatography and identified as the primary alcohol 12 (82\% yield) which was fully characterised. In principle the preparation of this derivative 12 provides the opportunity to introduce other functional groups at the 5' position of the ribofuranose fragment. However, attempts to scale-up this preparation resulted in much lower yields of the desired alcohol 12 and analysis of the mixture showed that the monoand tri- acetyl derivatives 14 and 15 were present in significant amounts. TBAF appeared to be promoting ester cleavage and also acyl group migration. ${ }^{8}$ In an earlier study of protected ribofuranosyl derivatives, Reese et al determined that benzoate esters are less prone to basecatalysed migration and cleavage than acetate groups. ${ }^{9}$ We therefore decided to employ more robust benzoyl protecting groups. Reaction of compound 9 with a large excess of benzoic 
anhydride in pyridine gave the diester 11 in $87 \%$ yield. Subsequent removal of the silylether protecting group using TBAF gave a single product that was isolated and identified as the desired alcohol 13 (76\%), identical to the sample prepared by the previous route.

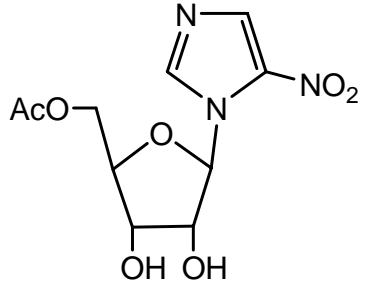

14

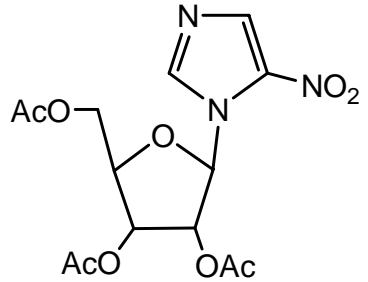

15

Since iodo functions are excellent radical triggers we next converted the alcohol 13 into the corresponding iodide. Compound 13 was dissolved in freshly dried pyridine and treated with methylsulphonyl chloride. Work-up and chromatography gave a syrup that was essentially a single product and was identified as the 5'-O-methylsulphonyl derivative 17 (70\% yield). The ${ }^{1} \mathrm{H}$ NMR spectrum showed a singlet at $\delta 3.15$ corresponding to the mesyl ester. In a similar manner the 2',3'-diacetoxy derivative 12 was converted to the mesyl ester 16 (86\% yield).

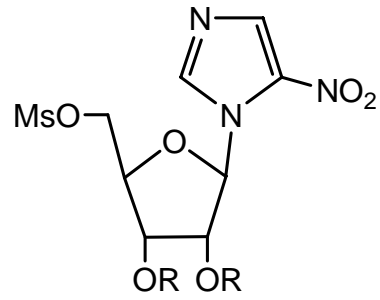

$\begin{aligned} \text { 16; } \mathrm{R} & =\mathrm{COMe} \\ \text { 17; } \mathrm{R} & =\mathrm{COPh}\end{aligned}$

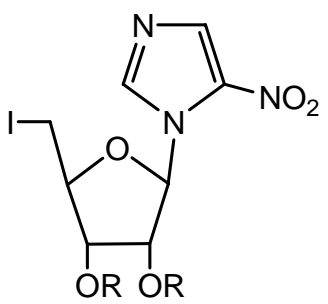

18; $\mathrm{R}=\mathrm{COMe}$

19; $\mathrm{R}=\mathrm{COPh}$

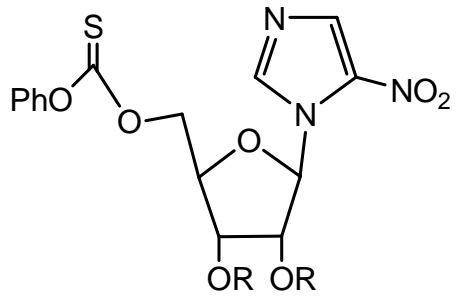

20; $\mathrm{R}=\mathrm{COPh}$

Treatment of the mesyl ester 17 with sodium iodide in hot, dry acetone gave after chromatography a single crystalline product. This was identified as the iodide 19, m.p. 178$180{ }^{\circ} \mathrm{C}$ (70\% yield) which was fully characterised. In a similar manner the iodide 18 was also obtained as a gummy syrup. However, we were not satisfied with the overall yield of the 2',3'dibenzoyloxy-5'-iodo derivative 19 and an alternative procedure was investigated. In particular we dissolved the alcohol 13, triphenylphosphine and imidazole in acetonitrile-diethyl ether and a solution of iodine in the same solvent was added with stirring. Work-up gave the iodide 19 (60\%) which was identical to an authentic sample.

In addition to compound 19, a second derivative containing a different radical trigger was prepared. Thus treatment of the alcohol 13 with phenoxythiocarbonyl chloride and DMAP in dry acetonitrile gave the thiocarbonate derivative 20 which was obtained as colourless needles, m.p. $126-129{ }^{\circ} \mathrm{C}(71 \%$ yield $)$ and fully characterised. 
Barton and co-workers ${ }^{10}$ have described the preparation of the conformationally restricted nucleoside precursors of adenosine 22 and uridine 24 using carbon radicals generated from the acyclic precursors 21 and $23(\mathrm{X}=\mathrm{TeAn})$. Earlier workers ${ }^{11}$ had made the adenosine analogue 22 by reductive cyclisation of the iodide $21(\mathrm{X}=\mathrm{I})$ and Matsuda and co-workers have made the cycloderivatives of adenosine and guanosine by photoirradiation of 5 '-phenylthio derivatives. ${ }^{12}$ It therefore seemed reasonable to attempt the formation of the cyclo-derivative 25 using the radical precursors 19 and 20 .

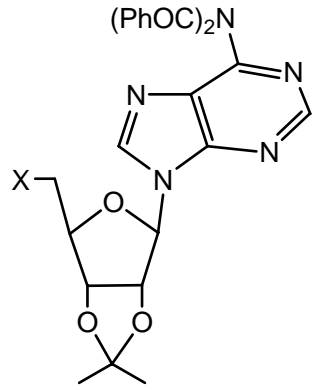

21

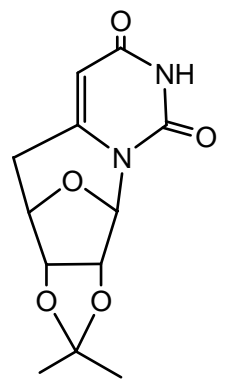

24

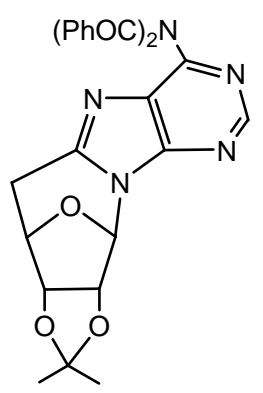

22

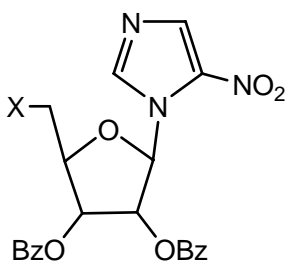

19; $\mathrm{X}=\mathrm{I}$

20; $\mathrm{X}=\mathrm{OCS} . \mathrm{OPh}$

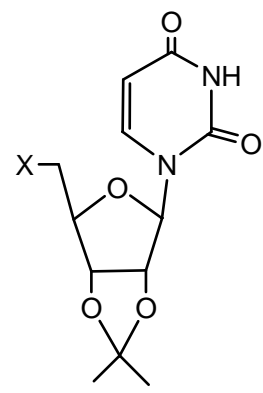

23

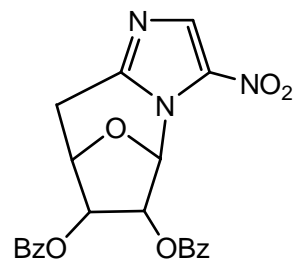

25

Reaction of the iodide 19 with tributyltin hydride ( 2 equiv.) in the presence of AIBN (0.3 equiv.) in degassed benzene at reflux temperature gave, after chromatography, one major component. This had a well defined ${ }^{1} \mathrm{H}$ NMR spectrum and appeared to have a molecular weight (FAB) of ca 579 mass units. This product remains unidentified but appears to still contain iodine and it is not the desired product 25 . When the thiocarbonate 20 was treated with tributyltin hydride under similar conditions a complex mixture was obtained and no products were identified or isolated. We conclude that the carbon radical generated from the precursors 19 and 20 does not readily cyclise to the desired product 25 . We now believe that the 5 -nitro substituent interferes with the desired process and is not compatible with the radical methodology.

\section{Experimental Section}

General Procedures. All solvents were purified and distilled before use. Acetonitrile was doubly distilled from $\mathrm{P}_{2} \mathrm{O}_{5}$ and then stored in a dark bottle over $4 \AA$ molecular sieves. THF was 
dried by refluxing over sodium until benzophenone held a purple colour. Thin layer chromatography (tlc) was carried out using foil backed alumina or silica plates. Flash column chromatography was carried out using Janssen silica gel (particle size 0.035-0.07mm). Chromatotron chromatography was performed on plates prepared using silica gel $60 \mathrm{PF}_{254}$

Melting points were determined on a Kofler melting point microscope apparatus and are uncorrected. Nuclear Magnetic Resonance (NMR) spectra were determined on a Jeol GSX 270 $\mathrm{MHz}$ FT spectrometer. Unless otherwise stated, NMR spectra were run in $\mathrm{CDCl}_{3}$ or $\mathrm{d}_{6}$-DMSO. Microanalyses were obtained on a Perkin Elmer 240 elemental analyser. Mass spectra were obtained on a AEI MS12 mass spectrometer at $70 \mathrm{eV}$. High resolution and Fast Atom Bombardment (FAB) mass spectra were recorded by the EPSRC Mass Spectrometry Service (Swansea). Infrared (IR) absorption spectra were recorded using either a Perkin-Elmer 881 or Perkin-Elmer Paragon FT-IR spectrophotometer: unless otherwise stated all solid samples were incorporated into $\mathrm{KBr}$ discs and liquid samples were dissolved in $\mathrm{CHCl}_{3}$.

Spectroscopic details were recorded for all compounds made; in those cases where a compound was obtained in more than one reaction and where starting materials were recovered, identification was confirmed by m.p. and IR.

1-(5'-O-t-Butyldiphenylsilyl- $\beta$-D-ribofuranosyl)-5-nitroimidazole (9). A solution of 1-( $\beta$-Dribofuranosyl)-5-nitroimidazole $3(150 \mathrm{mg}, 0.6 \mathrm{mmol})$ in dry DMF $(3 \mathrm{~mL})$ was stirred with triethylamine (100 mL, 1.2 equiv.) and DMAP (18 mg, 0.25 equiv,) under nitrogen. To this mixture was added dropwise TBDPSCl (180 mg, $174 \mathrm{~mL}, 1.1$ equiv.) with stirring. After $30 \mathrm{~min}$ a fine suspension was observed and after a further two hours tlc $\left(\mathrm{CHCl}_{3}: \mathrm{MeOH}, 9: 1\right.$ as eluant) showed the absence of starting material. Removal of the solvent followed by extraction with $\mathrm{CHCl}_{3}$ gave a pale syrup that was subjected to chromatography on silica $\left(\mathrm{CHCl}_{3}: \mathrm{MeOH} 9: 1\right.$ as eluant). The major band was collected to afford a colourless solid, which was recrystallised from petroleum ether (b.p. $\left.60-80{ }^{\circ} \mathrm{C}\right)$-EtOAc and identified as 1-(5'-O-t-butyldiphenylsilyl- $\beta$-Dribofuranosyl)-5-nitroimidazole 9 (185 mg, 62\%) m.p. $172-5{ }^{\circ} \mathrm{C} ; v_{\max }(\mathrm{KBr}) 3552,3322,2934$, 2858, 1530, 1474, 1430, 1416, 1370, 1216, 1108, 1058, 996, 878, 820, 796 and $708 \mathrm{~cm}^{-1} ;{ }^{1} \mathrm{H}$ NMR (270 MHz, d6-DMSO) $\delta 1.01\left(9 \mathrm{H}, \mathrm{s},\left(\mathrm{CH}_{3}\right)_{3} \mathrm{CSi}\right), 3.99$ (3 H, br m, 4'-H, 5'-CH $)$, 4.26 (2 $\left.\mathrm{H}, \mathrm{m}, 2^{\prime}, 3^{\prime}-\mathrm{H}\right), 5.78-5.23$ (2 x OH), 6.22 (1 H, s, 1'-H), 7.96-7.40 (10 H, br m, $\left.\mathrm{Ph}_{2} \mathrm{Si}\right), 8.12(1 \mathrm{H}$, $\mathrm{s}, 4-\mathrm{H}), 8.43(1 \mathrm{H}, \mathrm{s}, 2-\mathrm{H})$; $\lambda \max (\mathrm{EtOH}) 296.4 \mathrm{~nm}(\mathrm{e} 48928) ; \mathrm{m} / \mathrm{z}$ (FAB) $227\left(\mathrm{M}^{+} 255\right) 115$ $(\mathrm{b}+2 \mathrm{H})$ identical by mixed melting point and IR with an authentic sample prepared using a different procedure. ${ }^{4}$

1-(2',3'-Di-O-acetyl-5'-O-t-butyldiphenylsilyl- $\beta$-D-ribofuranosyl)-5-nitroimidazole (10). A mixture of 1-(5'-O-t-butyldiphenylsilyl- $\beta$-D-ribofuranosyl)-5-nitroimidazole $9(250 \mathrm{mg})$ and DMAP (0.25 equiv.) was dissolved in acetic anhydride $(5 \mathrm{~mL})$ with stirring $(3 \mathrm{~h})$. The reaction was continued until tlc showed an absence of starting material. Evaporation of excess reagent followed by the addition and evaporation of methanol $(2 \times 5 \mathrm{mLl})$ gave a syrup that was purified by chromatography on silica gel $\left(\mathrm{CHCl}_{3}: \mathrm{MeOH} 9: 1\right.$ as eluant) to give 1-(2',3'-di-O-acetyl-5'-O-tbutyldiphenylsilyl- $\beta$-D-ribofuranosyl)-5-nitroimidazole 10 as a pale syrup in quantitative yield; 
$v_{\max }\left(\mathrm{CHCl}_{3}\right)$ 3126, 2860, 1748, 1590, 1362, 1186, 1070 and $886 \mathrm{~cm}^{-1} ;{ }^{1} \mathrm{H}$ NMR (270 MHz, $\left.\mathrm{CDCl}_{3}\right)_{\delta} 1.07\left(9 \mathrm{H}, \mathrm{s},\left(\mathrm{CH}_{3}\right)_{3} \mathrm{Si}\right), 1.99\left(3 \mathrm{H}, \mathrm{s}, \mathrm{CH}_{3} \mathrm{CO}\right), 2.11\left(3 \mathrm{H}, \mathrm{s}, \mathrm{CH}_{3} \mathrm{CO}\right), 3.72-4.11(2 \mathrm{H}$, br m, 5'- $\left.\mathrm{CH}_{2}\right), 4.11$ (1 H, m, 4'-H), 5.55 (2 H, m, 2',3'-H), 6.48 (1 H, d, J 3.0 Hz, 1'-H), 7.37 (6 H, m, Ar), 7.61 (4 H, m, Ar), $8.03(1 \mathrm{H}, \mathrm{s}, 4-\mathrm{H}), 8.35$ (1 H, s, 2-H). This material was used without further purification.

1-(2',3'-Di-O-benzoyl-5'-O-t-butyldiphenylsilyl- $\beta$-D-ribofuranosyl)-5-nitroimidazole (11). A mixture of 1-(5'-O-t-butyldiphenylsilyl- $\beta$-D-ribofuranosyl)-5-nitroimidazole9 (0.6 g, $1.2 \mathrm{mmol})$, DMAP (0.25 equiv.) and benzoic anhydride (2.8 g, 10 equiv.) was dissolved in dry pyridine $(15 \mathrm{~mL})$ at $0{ }^{\circ} \mathrm{C}$ and then stirred overnight at room temperature. The mixture was poured onto ice $(50 \mathrm{~mL})$ and extracted with chloroform $(3 \times 20 \mathrm{~mL})$. The organic layer was dried $\left(\mathrm{Na}_{2} \mathrm{SO}_{4}\right)$ and evaporated to give a dark syrup. Separation by chromatography $\left(\mathrm{CHCl}_{3}: \mathrm{MeOH}\right.$ 9:1 as eluant) and collection of the fraction at $\mathrm{R}_{\mathrm{f}} 0.8$ gave a pale syrup that was identified as 1-(2',3'-di-Obenzoyl-5'-O-t-butyldiphenylsilyl- $\beta$-D-ribofuranosyl)-5-nitroimidazole 11 (0.7 g, 87\%); vmax $\left(\mathrm{CHCl}_{3}\right)$ 3410, 3152, 2998, 2932, 1816, 1726, 1464, 1418, 1376, 1180 and $894 \mathrm{~cm}^{-1}$; ${ }^{1} \mathrm{H}$ NMR $(270 \mathrm{MHz}, \mathrm{CDCl} 3)_{\delta} 1.10\left(9 \mathrm{H}, \mathrm{s},\left(\mathrm{CH}_{3}\right)_{3} \mathrm{Si}\right), 3.8-4.2\left(2 \mathrm{H}, \mathrm{br} \mathrm{m}, 5^{\prime}-\mathrm{CH}_{2}\right), 4.55\left(1 \mathrm{H}, \mathrm{m}, 4^{\prime}-\mathrm{H}\right)$, 5.96 (2 H, m, 2',3'-H), 6.85 (1 H, d, J 3.0 Hz, 1'-H), 7.3-8.2 (21 H, br m, 4-H, Ar), 8.46 (1 H, s, $2-\mathrm{H})$. This material was used without further purification.

1-(2',3'-Di-O-acetyl- $\beta$-D-ribofuranosyl)-5-nitroimidazole (12). To a solution of 1-(2',3'-di-Oacetyl-5'-O-t-butyldiphenylsilyl- $\beta$-D-ribofuranosyl)-5-nitroimidazole $10(0.1 \mathrm{~g}, 0.2 \mathrm{mmol})$ in dry THF $(3 \mathrm{~mL})$ was added dropwise a $1 \mathrm{M}$ solution of TBAF in THF $(0.2 \mathrm{~mL})$ with stirring $(1 \mathrm{~h})$. After this time tlc (EtOAc:petroleum ether (b.p. $60-80{ }^{\circ} \mathrm{C}$ ) 1:1 as eluant) showed an absence of starting material and purification by chromatography (EtOAc:petroleum ether (b.p. $60-80{ }^{\circ} \mathrm{C}$ ) 7:3 as eluant) gave three components. The major component collected at $\mathrm{R}_{\mathrm{f}} 0.5$ was evaporated, recrystallised from EtOAc:petroleum ether (b.p. $\left.60-80{ }^{\circ} \mathrm{C}\right)$ and identified as1-(2',3'-di-O-acetyl$\beta$-D-ribofuranosyl)-5-nitroimidazole 12 (80 mg, 82\%) as colourless needles; m.p. 138-140 ${ }^{\circ} \mathrm{C}$; ${ }_{v \max }(\mathrm{KBr}) 3382,3366,3130,2980,2952,1752,1546,1520,1468,1374,1242$ and $1080 \mathrm{~cm}^{-1} ;{ }^{1} \mathrm{H}$ NMR (270 MHz, $\left.\mathrm{CDCl}_{3}\right)_{\delta} 2.08\left(3 \mathrm{H}, \mathrm{s}, \mathrm{CH}_{3} \mathrm{CO}\right), 2.14\left(3 \mathrm{H}, \mathrm{s}, \mathrm{CH}_{3} \mathrm{CO}\right), 3.84-4.12(2 \mathrm{H}, \mathrm{br} \mathrm{m}$, 5'- $\left.\mathrm{CH}_{2}\right), 4.31$ (1 H, m, 4'-H), 5.52 (1 H, m, 3'-H), 5.63 (1 H, m, 2'-H), 6.53 (1 H, d, J 3.0 Hz, 1'H), 7.99 (1 H, s, 4-H), $8.62(1 \mathrm{H}, \mathrm{s}, 2-\mathrm{H}) ; \mathrm{m} / \mathrm{z}(\mathrm{FAB}) 330\left(\mathrm{M}^{+}+\mathrm{H}\right), 329\left(\mathrm{M}^{+}\right), 142\left(\mathrm{~b}+\mathrm{CH}_{2} \mathrm{O}\right), 115$ $(\mathrm{b}+2 \mathrm{H})$; Anal. calcd. for $\mathrm{C}_{12} \mathrm{H}_{15} \mathrm{~N}_{3} \mathrm{O}_{8}$ : C, 43.77; $\mathrm{H}, 4.56 ; \mathrm{N}, 12.77$. Found: $\mathrm{C}, 43.56 ; \mathrm{H}, 4.60 ; \mathrm{N}$, 12.91 .

A similar procedure using compound 11 gave 1-(2',3'-di-O-benzoyl- $\beta$-D-ribofuranosyl)-5nitroimidazole $13(76 \%)$, m.p. $168-170{ }^{\circ} \mathrm{C}$, full characterisation of which has been described elsewhere. ${ }^{4}$

1-(2',3'-Di-O-benzoyl-5'-O-methanesulphonyl- $\beta$-D-ribofuranosyl)-5-nitroimidazole (17). To 1-(2',3'-di-O-benzoyl- $\beta$-D-ribofuranosyl)-5-nitroimidazole13 (200 $\mathrm{mg}, 4.5 \mathrm{mmol})$ in dry pyridine $(6 \mathrm{~mL})$ at $0{ }^{\circ} \mathrm{C}$ was added methanesulphonyl chloride $(40 \mathrm{~mL}, 1.1$ equiv.) dropwise with stirring. After $15 \mathrm{~min}$ the temperature was allowed to rise to room temperature and stirring was continued overnight. Water $(10 \mathrm{~mL})$ was added and the mixture extracted with chloroform and then evaporated to give a dark syrup. Chromatography (petroleum ether (b.p. $60-80{ }^{\circ} \mathrm{C}$ ):EtOAc 7:3 as 
eluant) afforded a single product which was identified as 1-(2',3'-di-O-benzoyl-5'-Omethanesulphonyl- $\beta$-D-ribofuranosyl)-5-nitroimidazole 17 (160 $\mathrm{mg}, 70 \%)$ as a pale syrup; vmax $\left(\mathrm{CHCl}_{3}\right)$ 3012, 1740, 1604, 1474, 1364, 1204, 1120 and $802 \mathrm{~cm}^{-1} ;{ }^{1} \mathrm{H} \mathrm{NMR}\left(270 \mathrm{MHz}, \mathrm{CDCl}_{3}\right)_{\delta}$ 3.15 (3 H, s, $\left.\mathrm{CH}_{3} \mathrm{SO}_{2}\right), 4.54-4.71$ (3 H, br m, 4'H, 5'- $\left.\mathrm{CH}_{2}\right), 5.76$ (2 H, m, 2',3'-H), 6.80 (1 H, d, J $3.5 \mathrm{~Hz}, 1$ '-H), 7.28-7.98 (10 H, m, Ph), 8.05 (1 H, s, 4-H), 8.22 (1 H, s, 2-H). This material was used for the preparation of iodide 19 without further purification.

1-(2',3'-di-O-acetyl-5'-O-methanesulphonyl- $\beta$-D-ribofuranosyl)-5-nitroimidazole (16). 1 (2',3'-Di-O-acetyl- $\beta$-D-ribofuranosyl)-5-nitroimidazole12 (80 $\mathrm{mg}, 0.2 \mathrm{mmol}$ ) was dissolved in dry pyridine $(3 \mathrm{~mL})$ and the mixture cooled on ice. Methanesulphonyl chloride $(18 \mathrm{~mL}$, $0.24 \mathrm{mmol}$ ) was added dropwise with stirring. The mixture was stirred overnight at room temperature. Water $(10 \mathrm{~mL})$ was then added and the mixture extracted with $\mathrm{CHCl}_{3}$, washed with water $(10 \mathrm{~mL})$ and dried $\left(\mathrm{MgSO}_{4}\right)$. Analysis by tlc (EtOAc:petroleum ether (b.p. $\left.60-80{ }^{\circ} \mathrm{C}\right)$ 7:3 as eluant) showed the clean production of only one product and evaporation of the solvent gave a pale syrup which was identified as 1-(2',3'-di-O-acetyl-5'-O-methanesulphonyl- $\beta$-Dribofuranosyl)-5-nitroimidazole 16 (70 mg, 86\%); vmax $\left(\mathrm{CHCl}_{3}\right)$ 3136, 3020, 2968, 1758, 1674, 1506, 1468, 1370, 1226, 1178 and $908 \mathrm{~cm}^{-1}$; ${ }^{1} \mathrm{H}$ NMR (270 MHz, CDCl3) $\delta 2.09$ (3 H, s, $\mathrm{CH}_{3} \mathrm{CO}$ ). 2.16 (3 H, s, $\left.\mathrm{CH}_{3} \mathrm{CO}\right), 3.12\left(3 \mathrm{H}, \mathrm{s}, \mathrm{CH}_{3} \mathrm{SO}_{2}\right), 4.48\left(2 \mathrm{H}, \mathrm{m}, 5^{\prime}-\mathrm{CH}_{2}\right), 4.63$ (1 H, m, 4'H), 5.42 (1 H, m, 3'-H), 5.53 (1 H, m, 2'-H), 6.51 (1 H, d, J 3.0 Hz, 1'-H), 8.05 (1 H, s, 4-H), 8.14 $(1 \mathrm{H}, \mathrm{s}, 2-\mathrm{H})$. This material was used without further purification.

\section{1-(2',3'-Di-O-benzoyl-5'-iodo- $\beta$-D-ribofuranosyl)-5-nitroimidazole (19)}

Method A. A mixture of 1-(2',3'-di-O-benzoyl-5'-O-methanesulphonyl- $\beta$-D- ribofuranosyl)-5nitroimidazole 17 (160 mg, $0.3 \mathrm{mmol})$ and sodium iodide $(0.46 \mathrm{~g}, 10$ equiv.) in acetone $(10 \mathrm{~mL})$ was heated under reflux (6 h). After this time tlc (petroleum ether (b.p. 60-80 ${ }^{\circ} \mathrm{C}$ ):EtOAc 7:3 as eluant) showed an absence of starting material. The reaction was stopped and the mixture cooled to room temperature. Following filtration and evaporation the residue was extracted with chloroform and chromatographed (petroleum ether (b.p. $60-80{ }^{\circ} \mathrm{C}$ ):EtOAc 7:3 as eluant) to yield a single product that was identified as 1-(2',3'-di-O-benzoyl-5'-iodo- $\beta$-D-ribofuranosyl)-5nitroimidazole 19 (120 mg, 70\%), colourless crystals; m.p. 178-180 ${ }^{\circ} \mathrm{C}$; vmax (KBr) 2406, 2118, 1732, 1526, 1468, 1374, 1274, 1218, 1120, 1020 and $710 \mathrm{~cm}^{-1} ;{ }^{1} \mathrm{H} \mathrm{NMR}\left(270 \mathrm{MHz}, \mathrm{CDCl}_{3}\right) \delta$ 3.69 (2 H, m, 5'-CH $), 4.42$ (1 H, m, 4'-H), 5.58 (1 H, m, 3'-H), 5.82 (1 H, m, 2'-H), 6.88 (1 H, d, J 4.0 Hz, 1'-H), 7.32-7.97 (10 H, br m, Ar), 8.08 (1 H, s, 4-H), 8.39 (1 H, s, 2-H); m/z (FAB) 564 $\left(\mathrm{M}^{+}+\mathrm{H}\right), 451\left(\mathrm{M}^{+}+\mathrm{H}-\mathrm{b}\right), 113$ (b); Anal. calcd. for $\mathrm{C}_{22} \mathrm{H}_{18} \mathrm{~N}_{3} \mathrm{O}_{7} \mathrm{I}$ : C, 46.8; H, 3.2; N, 7.4. Found: C, 46.91; H, 3.33; N, 7.40.

Method B. To a solution 1-(2',3'-di-O-benzoyl- $\beta$-D-ribofuranosyl)-5-nitroimidazole13 (100 mg, $2.2 \mathrm{mmol})$ in acetonitrile:ether 3:5 (5 mL) was added triphenylphosphene (75 $\mathrm{mg}, 2.8 \mathrm{mmol}, 1.3$ equiv.) and imidazole (16 mg, 1.3 equiv.) (both reagents freshly recrystallised) with stirring. To this mixture was then added iodine (39 mg, 1.4 equiv.) in the same solvent mixture $(5 \mathrm{~mL})$. After stirring overnight at room temperature, analysis by tlc showed little starting material and a new product at a higher $R_{f}$. The mixture was diluted with diethyl ether $(10 \mathrm{~mL})$ and washed successively with aqueous sodium sulphite, aqueous copper sulphate and water, before drying 
$\left(\mathrm{MgSO}_{4}\right)$. Evaporation of the solvent gave a residue that was chromatographed (EtOAc:petroleum ether (b.p. $60-80{ }^{\circ} \mathrm{C}$ ) 7:3 as eluant) to give two products. The major product was identified as 1-(2',3'-di-O-benzoyl-5'-iodo- $\beta$-D-ribofuranosyl)-5-nitroimidazole 19 (74 mg, $60 \%$ ), colourless crystals, m.p. $178-180{ }^{\circ} \mathrm{C}$, identical by mixed melting point and IR with an authentic sample prepared using Method A. The second component was identified as starting material 13 (40 mg, 35\%).

1-(2',3'-Di-O-acetyl-5'-iodo- $\beta$-D-ribofuranosyl)-5-nitroimidazole (18). A mixture of 1-(2',3'di-O-acetyl-5'-O-methanesulphonyl- $\beta$-D-ribofuranosyl)-5-nitroimidazole 16 (50 mg, $0.012 \mathrm{~mol}$ ) and sodium iodide (180 mg, 10 equiv.) was dissolved in dry acetone $(5 \mathrm{~mL})$ and stirred under reflux $(6 \mathrm{~h})$. After this time analysis by tlc (EtOAc:petroleum ether 7:3 (b.p. $60-80{ }^{\circ} \mathrm{C}$ ) as eluant) showed the absence of starting material and the appearance of a new product at higher $\mathrm{R}_{\mathrm{f}}$. The reaction was stopped and the yellow solution cooled to room temperature, filtered and evaporated to give a sticky solid. The residue was subjected to chromatography on silica (EtOAc:petroleum ether (b.p. $60-80{ }^{\circ} \mathrm{C}$ ) 7:3 as eluant) and a single product collected. Evaporation of the solvent afforded a gummy syrup which was identified as 1-(2',3'-di-O-acetyl5'-iodo- $\beta$-D-ribofuranosyl)-5-nitroimidazole18 (48 mg); ${ }^{1} \mathrm{H}$ NMR showed the absence of the $\mathrm{CH}_{3} \mathrm{SO}_{2}$ signal at $\delta 3.1 ;$ vmax $\left(\mathrm{CHCl}_{3}\right) 2958,2254,1760,1468,1422,1246,906$ and 862, $906 \mathrm{~cm}^{-}$ ${ }^{1} ;{ }^{1} \mathrm{H} \mathrm{NMR}\left(\mathrm{CDCl}_{3}\right) \delta 2.10\left(3 \mathrm{H}, \mathrm{s}, \mathrm{CH}_{3} \mathrm{CO}\right), 2.15\left(3 \mathrm{H}, \mathrm{s}, \mathrm{CH}_{3} \mathrm{CO}\right), 3.51\left(2 \mathrm{H}, \mathrm{m}, 5^{\prime}-\mathrm{CH}_{2}\right), 4.16$ (1 H, m, 4'-H), 5.19 (1 H, m, 3'-H), 5.53 (1 H, m, 2'-H), 6.53 (1 H, d, J 3.5 Hz, 1'-H), 8.05 (1 H, s, 4-H), 8.27 (1 H, s, 2-H).

1-(2',3'-Di-O-benzoyl-5'-O-phenoxythiocarbonyl- $\beta$-D-ribofuranosyl)-5-nitroimidazole (20). A mixture of 1-(2',3'-di-O-benzoyl- $\beta$-D-ribofuranosyl)-5-nitroimidazole 13 (80 mg, $0.17 \mathrm{mmol}$ ) and DMAP (100 mg, 5 equiv.) was dissolved in dry acetonitrile (5 mL) and stirred (5 min). Phenoxythiocarbonyl chloride (26 mL, $0.19 \mathrm{mmol}, 1.1$ equiv.) was then added dropwise and the mixture stirred for a further $2 \mathrm{~h}$. After this time tlc (EtOAc:petroleum ether (b.p. $60-80{ }^{\circ} \mathrm{C}$ ) 1:1 as eluant) of the reaction mixture showed an absence of any starting material and the appearance of a new intense spot at $R_{f}$ 0.8. The solvent was evaporated and the residue dissolved in EtOAc. The solution was washed with aqueous $\mathrm{NaHCO}_{3}$, brine and then dried $\left(\mathrm{Na}_{2} \mathrm{SO}_{4}\right)$. Evaporation of the solvent gave a syrup which was chromatographed (EtOAc:petroleum ether (b.p. $60-80{ }^{\circ} \mathrm{C}$ ) 1:1 as eluant). The major product was recrystallised from petroleum ether (b.p. $60-80{ }^{\circ} \mathrm{C}$ ) and identified as 1-(2',3'-di-O-benzoyl-5'-O-phenoxythiocarbonyl- $\beta$-D-ribofuranosyl)-5-nitroimidazole20 (70 mg, 71\%) as colourless needles; m.p. 126-129 ${ }^{\circ} \mathrm{C} ; v_{\max }(\mathrm{KBr}) 3142,2961,1734,1603,1531,1456,1373,1261,1122$ and $1038 \mathrm{~cm}^{-1} ;{ }^{1} \mathrm{H}$ NMR $\left(\mathrm{CDCl}_{3}\right) \delta 4.82\left(1 \mathrm{H}, \mathrm{m}, 4^{\prime}-\mathrm{H}\right), 4.93\left(2 \mathrm{H}, \mathrm{m}, 5^{\prime}-\mathrm{CH}_{2}\right), 5.84\left(2 \mathrm{H}, \mathrm{m}, 2^{\prime}, 3^{\prime}-\mathrm{H}\right), 6.86(1 \mathrm{H}$, d, J 3.5 Hz, 1'-H), 7.14-7.59 (11 H, br m, Ar, PhOCS), 7.9-8.0 (4 H, m, Ar), 8.06 (1 H, s, 4-H), 8.24 $(1 \mathrm{H}, \mathrm{s}, 2-\mathrm{H}) ; \mathrm{m} / \mathrm{z}(\mathrm{FAB}) 589\left(\mathrm{M}^{+}\right), 590\left(\mathrm{M}^{+}+\mathrm{H}\right)$; HRMS $\mathrm{C}_{29} \mathrm{H}_{23} \mathrm{~N}_{3} \mathrm{O}_{9} \mathrm{SNa}$ requires 612.1052. Found: $612.1069\left(\mathrm{M}^{+}+\mathrm{Na}\right)$.

Reactions utilising AIBN

A mixture of 1-(2',3'-di-O-benzoyl-5'-iodo- $\beta$-D-ribofuranosyl)-5-nitroimidazole 19 (90 mg, $1.59 \mathrm{mmol})$, tributyltin hydride $(85 \mathrm{~mL}, 3.19 \mathrm{mmol}, 2$ equiv.) and AIBN (7 mg, 0.3 equiv.) was heated under reflux in de-gassed benzene $(20 \mathrm{~mL})$ for $24 \mathrm{~h}$. After this time the solution had 
darkened and tlc (EtOAc:petroleum ether (b.p. $60-80{ }^{\circ} \mathrm{C}$ ) as eluant) showed the absence of starting material. The solvent was removed to give a dark gummy residue that was chromatographed on silica (EtOAc:petroleum ether (b.p. 60-80 ${ }^{\circ} \mathrm{C}$ ) as eluant). The major component was collected and submitted for NMR and mass spectrometry but this product remains unidentified. ${ }^{1} \mathrm{H}$ NMR $\left(d_{6}\right.$-DMSO) $\delta 1.43(2 \mathrm{H}, \mathrm{s}), 4.59(1 \mathrm{H}, \mathrm{m}), 4.85(1 \mathrm{H}, \mathrm{m}), 6.23$ (1 H, m), 6.35 (1 H, m), 7.05 (1 H, d, J 3.5Hz), 7.50 (4 H, m), 7.70 (2 H, m), 7.89 (4 H, m), 8.24 (1 $\mathrm{H}, \mathrm{s}), 8.38(1 \mathrm{H}, \mathrm{s}) ; \mathrm{m} / \mathrm{z}(\mathrm{FAB}) 579\left(\mathrm{M}^{+} / \mathrm{M}^{+}+\mathrm{H}\right)$.

\section{Acknowledgements}

We thank the EPSRC for the award of a studentship (to MJH) and the EPSRC National Mass Spectrometry Service Centre for high-resolution mass spectra.

\section{References}

1. (a) Lythgoe, D.J.; Ramsden, C.A. Adv. Heterocyl. Chem. 1994, 61, 1. (b) Ramsden, C.A. Chem. Heterocyl. Compounds 1995, 1323.

2. Al-Shaar, A.H.M.; Gilmour, D.W.; Lythgoe, D.J.; McClenaghan, I.; Ramsden, C.A. J. Chem. Soc., Perkin Trans. 1 1992, 2779.

3. Al-Shaar, A.H.M.; Chambers, R.K.; Gilmour, D.W.; Lythgoe, D.J.; McClenaghan, I.; Ramsden, C.A. J. Chem. Soc., Perkin Trans. 1 1992, 2789.

4. Humphries, M.J.; Ramsden, C.A. Synthesis 1999, 985.

5. Lin, L-G.; Bakthavachalam, V.; Cherian, X.M.; Czarnik, A.W. J. Org. Chem. 1987, 52, 3113.

6. Miyashita, M.; Yoshikoshi, A.; Grieco, P.A. J. Org. Chem. 1977, 42, 3772.

7. Reese, C.B. In Nucleic Acids and Molecular Biology, Springer, Berlin, 1989, p 164.

8. Collins, P.M.; Ferrier, R.J. Monosaccharides: Their Chemistry and Their Roles in Natural Products, Wiley, Chichester, 1995; p 357.

9. Fromageot, H.P.M.; Reese, C.B.; Sulston, J.E. Tetrahedron 1968, 24, 3533.

10. Barton, D.H.R.; Géro, S.D.; Quiclet-Sire, B.; Samadi, M.; Vincent, C. Tetrahedron 1991, 47, 9383.

11. Zykber, J.; Pontikis, R.; Merrien, A.; Merienne, C.; Baran-Marszak, M.; Gaudemer, A. Tetrahedron 1980, 36, 1579.

12. Matsuda, A.; Tezuka, M.; Niizuma, K.; Sugiyama, E.; Ueda, T. Tetrahedron 1978, 34, 2633. 